\title{
Surgical vs. non-surgical management of displaced type-2 odontoid fractures in patients aged 75 years and older: study protocol for a randomised controlled trial
}

Anna-Lena Robinson ${ }^{1,2,5^{*}}$ (D) Gregor Schmeiser ${ }^{1,3}$, Yohan Robinson ${ }^{1,4}$ and Claes Olerud ${ }^{1}$

\begin{abstract}
Background: Displaced odontoid fractures in the elderly are treated non-surgically with a cervical collar or surgically with C1-C2 fusion. Due to the paucity of evidence, the treatment decision is often left to the discretion of the expert surgeon.

Methods: The Uppsala Study on Odontoid Fracture Treatment (USOFT) is a multicentre, open-label, randomised controlled superiority trial evaluating the clinical superiority of the surgical treatment of type-2 odontoid fractures, with a 1-year Neck Disability Index (NDI) as the primary endpoint. Fifty consecutive patients aged $\geq 75$ years, with displaced type-2 odontoid fracture, are randomised to non-surgical or surgical treatment. Excluded are patients with an American Society of Anaesthesiologists (ASA) score $\geq 4$, dementia nursing care or anatomical cervical anomalies.

The minimal clinically important difference of the NDI is 3.5 points. A minimum of 16 patients are needed in each group to test the superiority with $80 \%$ power. By considering a 1-year mortality forecast of $29 \%$, up to 25 participants are recruited in each group.

The non-surgical group is fitted with a rigid cervical collar for 12 weeks. The surgical group is treated with a posterior C1-C2 fusion. All participants are monitored with regard to the NDI, EuroQol score (EQ-5D), socio-demographics and computed tomography (CT) at the time of injury, at 6 weeks, 3 months and 12 months. At 12 months, a dynamic radiographical investigation of upper cervical stability is performed.

The secondary endpoints are: EQ-5D score, activities of daily living (ADL), bony union, upper cervical stability and mortality.

Discussion: USOFT is the first randomised controlled trial comparing non-surgical and surgical management of type-2 odontoid fractures in the elderly. Using the NDI and EQ-5D as endpoints, future value-based decisions may consider quality-adjusted life years gained. Major limitations are (1) the allocation bias of the open-label study design, (2) that only higher training levels of all core specialties of spine surgery are included in the surgical treatment arm and (3) that only one type of surgical stabilisation is investigated (posterior C1-C2 fusion), while other methods are not included in this study.
\end{abstract}

Trial registration: ClinicalTrials.gov, NCT02789774. Registered retrospectively on 25 August 2015.

Keywords: Odontoid fractures, Elderly, Osteoporosis, Spinal fractures, Surgical treatment

\footnotetext{
* Correspondence: anna-lena.robinson@spinecenter.se

${ }^{1}$ Department of Surgical Sciences, Uppsala University Hospital, Uppsala,

Sweden

${ }^{2}$ Stockholm Spine Center, Stockholm, Sweden

Full list of author information is available at the end of the article
}

(c) The Author(s). 2018 Open Access This article is distributed under the terms of the Creative Commons Attribution 4.0 International License (http://creativecommons.org/licenses/by/4.0/), which permits unrestricted use, distribution, and reproduction in any medium, provided you give appropriate credit to the original author(s) and the source, provide a link to the Creative Commons license, and indicate if changes were made. The Creative Commons Public Domain Dedication waiver (http://creativecommons.org/publicdomain/zero/1.0/) applies to the data made available in this article, unless otherwise stated. 


\section{Background}

\section{Background and rationale}

Unstable injuries to the upper cervical spine are a hazard to every elderly person, since associated dysphagia and respiratory restrictions are potential deadly complications [1]. The most common upper cervical fracture in elderly people aged $\geq 70$ years is the type- 2 odontoid fracture, with an incidence of 15.6 per 100,000 person-years in 2014 [2]. As with other osseous injuries in the elderly, the occurrence of odontoid fractures has been related to fragility, osteoporosis and falls [3]. The mortality of odontoid fractures, meanwhile, is strongly related to age, gender, comorbidity and type of treatment [4].

The treatment of displaced type- 2 odontoid fractures in the elderly varies from external orthosis treatment with a rigid collar to surgery, including anterior screw osteosynthesis and posterior $\mathrm{C} 1-\mathrm{C} 2$ fusion. Some earlier non-randomised studies have shown no significant difference between surgical treatment or non-surgical treatment regarding functional outcome (NDI, Neck Disability Index) or functional outcome score), pain and patient satisfaction $[5,6]$ the AOSpine North America Geriatric Odontoid Fracture (GOF) study has found significantly better outcomes measuring the NDI and the SF-36 Bodily Pain dimension comparing non-surgically and surgically treated patients [7]. Despite the fatal implications of inaccurate treatment, the most recent treatment recommendations vary widely, while surgeon adherence is highly dependent on regional differences [8]. There is a trend towards non-surgical treatment in Sweden; the fear of overtreatment could be a contributing factor. Patient comorbidity could be another explanation for physicians' tendency to use a cervical collar in the belief that this will avoid further damage. It could also be the tradition of the clinic that determines what treatment the patient should receive.

\section{Evidence}

On 30 October 2017, a search in PubMed was performed with the search term "odontoid[Title] OR dens[Title] AND fracture[title]". Of the 321 search results published between 1985 and 2017, only two prospective study were identified $[7,9,10]$. In the first prospective observational study, on percutaneous transarticular atlantoaxial screw fixation, 20 consecutive, multimorbid patients aged $>65$ years with a type- 2 odontoid fracture were included and followed for a minimum of 18 months [9]. The results from the study showed $88 \%$ healing of the fracture and $15 \%$ mortality within 3 months. In the other study 159 patients with a type- 2 odontoid fracture were included in a multicentre prospective study, comparing surgical $(n=101)$ and non-surgical $(n=58)$ treatment. Treatment choice was determined by the physician and/or the patient. The subjects were followed at 6 and 12 months with outcome measures, including the Neck Disability Index (NDI) and Short Form-36v2 (SF-36v2). They found that the functional outcome was significantly better in the surgically treated patients [7].

There were three ongoing prospective studies (including USOFT) registered at the ClinicalTrials.gov database (status: recruiting, NCT02281994, NCT02800278, NCT02789774). Meta-analyses of the survival from type- 2 odontoid fractures among the elderly aged $\geq 65$ years report better survival for patients who are treated surgically (Hazard ratio $(\mathrm{HR})=0.64)$ [4], while this seems to diminish if only those aged $\geq 80$ years are included [11]. Due to the retrospective nature of most published studies, considerable reporting and selection bias must be assumed, meaning that the strength of current treatment recommendations is questionable.

\section{Implications of this study}

Previously published and ongoing studies are focussed on non-union and mortality in relation to different treatment modalities. Nowadays, value-based care requires health-related quality of life (HRQoL) measures to influence health policy and decision-makers. By studying HRQoL and the function of patients with type-2 odontoid fractures, while comparing non-surgical treatment and the most common surgical treatment (posterior $\mathrm{C} 1-\mathrm{C} 2$ fusion), we can address the cost-effectiveness of the treatment options.

\section{Methods \\ Study aims and objectives \\ Primary objective}

The primary objective is to compare neck disability at 1 year after non-surgical treatment with surgical treatment of displaced type-2 odontoid fractures.

\section{Secondary objective}

The secondary objectives are to compare the cost-effectiveness, the mortality, the HRQoL and the bony union of non-surgical with surgical treatment after 1 year.

\section{Trial design}

The Uppsala Study on Odontoid Fracture Treatment (USOFT) is a multicentre, open-label, randomised controlled superiority trial. The protocol follows the Standard Protocol Items: Recommendations for Interventional Trials (SPIRIT) Statement for clinical trial reporting (Additional file 1) [12].

\section{Study setting}

The USOFT is being conducted in five departments of orthopaedic surgery in three university hospitals (Uppsala University Hospital, Malmö University Hospital and Karolinska University Hospital Stockholm) in Sweden. Participating university hospitals are level 1 trauma centres. All 
treating spine surgeons are orthopaedic or neurosurgical specialists with different levels of clinical experience in treating upper cervical spinal conditions.

\section{Eligibility criteria}

Inclusion criteria

Patients are eligible for inclusion in this study if they meet all of the following criteria:

- Acute displaced odontoid fracture, type 2 [13]

Displacement is measured on a multiplanar reconstruction of a cervical spine $\mathrm{CT}$ scan and defined as a $5-\mathrm{mm}$ anterior translator displacement, any posterior translator displacement or $10^{\circ}$ of angulation [14-17]

- Age: 75 years or older

\section{Exclusion criteria}

Patients are not included in this study if they meet one or more of the following criteria:

- ASA class 4 or higher $[18,19]$

- Severe dementia

Defined as being admitted to a nursing home or hospital because of dementia

- Anatomical anomalies (i.e. occipitocervical assimilation)

- Injuries (i.e. spinal cord injury (SCI) or severe dislocation threatening $\mathrm{SCI}$ ) that mandate surgery

\section{Interventions}

\section{Concomitant treatment in both groups}

- Collar in emergency department (Stifneck, Laerdal Medical, Stockholm Sweden)

- Pain medication (bolus: 2-5 mg morphine by the intravenous (IV) route)

- Diagnostic workup

- Baseline data collection according to Fig. 2

- Expertise of participating physicians: beginner (residents) to expert (consultant)

- Follow-up after 6 weeks, 3 months and 1 year, according to Fig. 2

\section{Non-surgical treatment}

The patient will be provided with a well-fitted and rigid collar, such as the Philadelphia collar (Ossur, Sollentuna, Sweden) or the Aspen collar (Aspen Medical Collars, Irvine, CA, USA). The collar will be worn $24 \mathrm{~h}$ a day for 12 weeks. The collar may be removed for short periods of time for personal hygiene when the patient is supine in bed.

CT scans will be repeated after 1 week, 6 weeks and 3 months. In case of increasing fracture displacement, or symptomatic non-union, the fracture will be treated surgically with a posterior $\mathrm{C} 1-\mathrm{C} 2$ fusion. The crossover will be documented, but all data will be analysed according to the intention-to-treat (ITT) principle.

\section{Surgical treatment}

The patient will be surgically treated with an instrumented posterior $\mathrm{C} 1-\mathrm{C} 2$ fusion, including an autologous iliac crest bone graft. The primary fixation technique involves transarticular $\mathrm{C} 1-\mathrm{C} 2$ screws, according to Magerl, and the $\mathrm{C} 1$ claw device [20]. In case of anatomical aberrations or a concomitant $\mathrm{C} 1$ arch fracture, other techniques may be used: e.g., C1 screws, according to Goel-Harms [21, 22], or translaminar C2 screws, according to Wright [23].

\section{Study outcome measures Primary outcome measure}

The primary outcome variable is the difference in the Neck Disability Index (NDI) at baseline and 1 year after injury $[24,25]$. Both comparing differences within the groups (baseline vs. NDI at 1 year), but also differences between the groups. The same evaluation will be made at 6 weeks and 3 months.

\section{Secondary outcome measures}

- EQ-5D score

- Katz ADL (Activities of Daily Living score) at baseline and at 1 year

- Visual Analogous Scale (VAS) at baseline and at 1 year

- Mortality

- Serious adverse events (including death) during the first year

- Radiographically demonstrable healing on CT after 1 year

- Upper cervical stability on dynamic flexion-extension radiographs of the cervical spine after 1 year

\section{Subgroup analysis}

- Socio-demographics

Age

Gender (male/female)

Body Mass Index (BMI)

American Society of Anaesthesiologists (ASA) class

Smoking (yes/no)

- Type-2 odontoid fracture subgroup

Grauer classification [15]

- Type of posterior C1-C2 fusion

Goel-Harms technique or Magerl-Atlas claw technique

- Osteoporosis (dual energy $\mathrm{x}$-ray absorptiometry (DXA) score) 


\section{Participant timeline}

The Consolidated Standards of Reporting Trials (CONSORT) inclusion flow diagram is presented in Fig. 1 [26]. The USOFT participant timeline is described in Fig. 2.

\section{Recruitment}

The history and physical examinations of all patients scheduled for surgery are screened preoperatively for predictors of difficult airways. Patient recruitment is conducted by a physician, while patient-reported follow-up is controlled by a qualified study nurse.

\section{Assignment of intervention \\ Allocation}

When a patient with an eligible type- 2 odontoid fracture seeks care at the hospital, the surgeon in charge of emergency care will contact the study group who inform the patient about the study and obtains their informed consent (Additional file 2). If the patient is unable to give

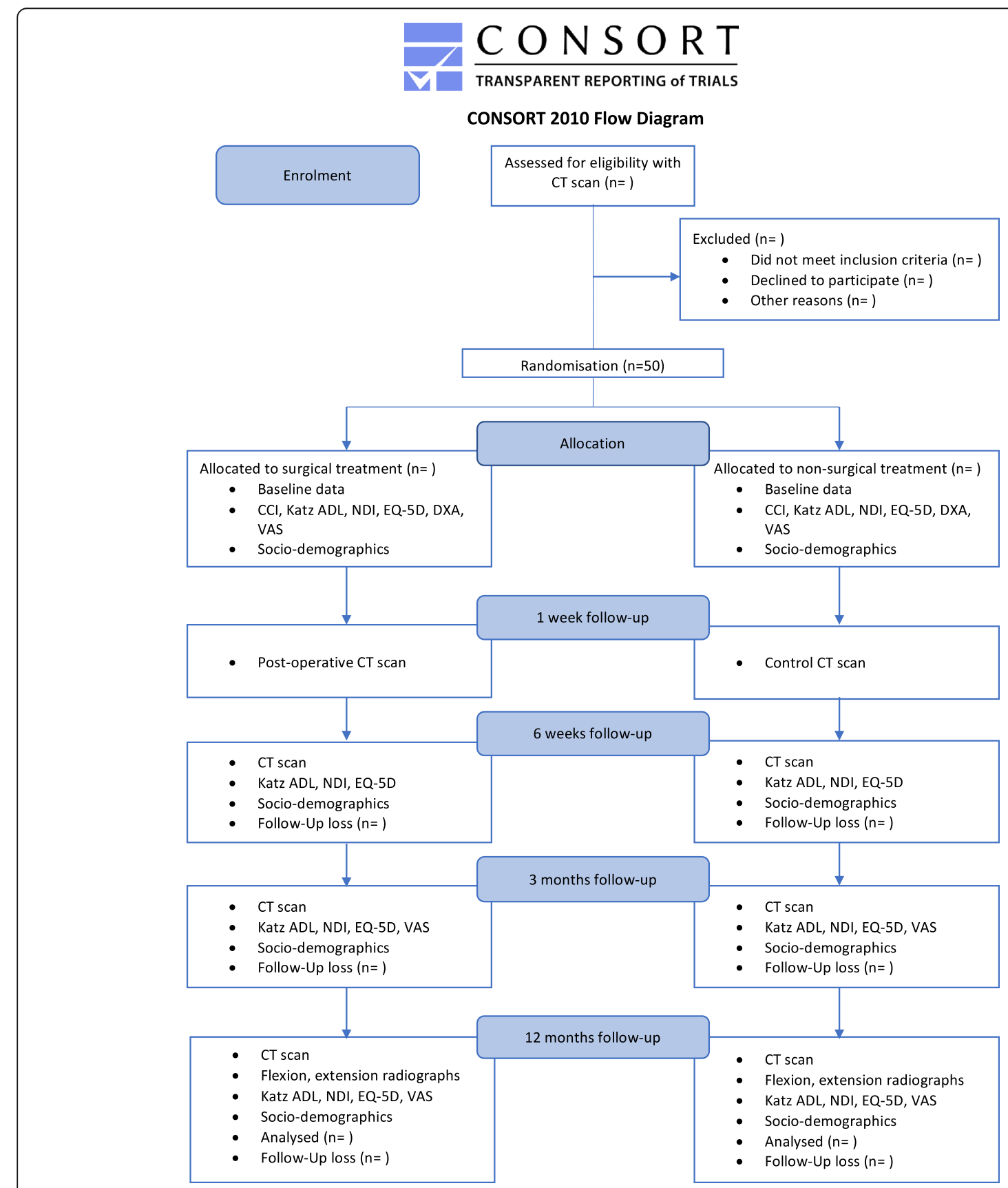

Fig. 1 Consolidated Standards of Reporting Trials (CONSORT) inclusion flow diagram 


\begin{tabular}{|c|c|c|c|c|c|c|}
\hline \multirow[b]{3}{*}{ Time point } & \multicolumn{6}{|c|}{ Study period } \\
\hline & \multirow{2}{*}{$\begin{array}{c}\text { Enrolment } \\
\text { day } 0\end{array}$} & \multirow{2}{*}{$\begin{array}{l}\text { Intervention } \\
\text { day } 1\end{array}$} & \multicolumn{4}{|c|}{ Follow-up } \\
\hline & & & week 2 & week 6 & week 12 & 1 year \\
\hline $\begin{array}{l}\text { Eligibility } \\
\text { assessment }\end{array}$ & $x$ & & & & & \\
\hline $\begin{array}{l}\text { Physical } \\
\text { examination }\end{array}$ & $x$ & & & & & \\
\hline CT scan & $\mathrm{x}$ & & $\mathrm{x}$ & $\mathrm{x}$ & $\mathrm{x}$ & $\mathrm{x}$ \\
\hline $\begin{array}{l}\text { Informed } \\
\text { consent }\end{array}$ & $\mathrm{x}$ & & & & & \\
\hline Randomisation & $\mathrm{x}$ & & & & & \\
\hline $\begin{array}{l}\text { Allocation } \\
\text { 1.surgery/2.non } \\
\text {-surgery }\end{array}$ & & $x$ & & & & \\
\hline Blood samples & & $x$ & & & & \\
\hline $\mathrm{CCl}$ & & $x$ & & & & \\
\hline NDI & & $x$ & & $\mathrm{x}$ & $x$ & $x$ \\
\hline EQ5D & & $\mathrm{x}$ & & $\mathrm{x}$ & $\mathrm{x}$ & $\mathrm{x}$ \\
\hline Katz ADL & & $\mathrm{x}$ & & $\mathrm{x}$ & $\mathrm{x}$ & $\mathrm{x}$ \\
\hline $\begin{array}{l}\text { Socio- } \\
\text { demographic } \\
\text { data }\end{array}$ & & $x$ & & $x$ & $x$ & $x$ \\
\hline DXA & & $x$ & & & & \\
\hline $\begin{array}{l}\text { Flexion, } \\
\text { extension } \\
\text { radiograph }\end{array}$ & & & & & & $x$ \\
\hline
\end{tabular}

Fig. 2 Participant timeline. CT computed tomography, CCl charlson comorbidity index, EQ-5D euroQol, NDI neck disability index, katz ADL activities in daily life according to katz, DXA double x-ray absorptiometry

informed consent, a close relative will be asked to give permission. Allocation is randomised using a sequentially numbered, opaque, sealed envelope (SNOSE) technique [27]. For obvious reasons, this study is not blinded.

If the patient/relative chooses not to participate in the USOFT, the patient is treated with a rigid collar, i.e. the present treatment at the department. Socio-demographic and clinical data will be collected. After acute treatment and mobilisation, the patient will be discharged to a suitable level of care in a normal way.

\section{Sequence generation}

Simple randomisation will be used to generate the allocation sequence. Randomisation is concealed using a SNOSE technique. Once a patient has given written consent, the next envelope according to the numbered sequence is opened and the patient is treated according to the allocated treatment.

\section{Blinding}

Blinding is not possible.

\section{Study instruments}

\section{Neck Disability Index}

The NDI quantifies neck-related disability on a score from 0 (no disability) to 50 (maximum disability) [24]. The results are then transformed into percentages (50 point $=100 \%$ disability). As many of the patients aged $\geq 75$ years no longer drive a car, question 8 , which concerns driving a car, may be excluded, resulting in a maximum score of 45 . The minimal clinically important difference (MCID) of the NDI is 3.5 points, with a standard deviation (SD) of 3.5 points [28]. The modified Swedish version of the NDI has been tested, showing good validity, sensitivity, test-retest reliability and specificity [25].

EuroQol health-related quality of life questionnaire (EQ-5D) EQ-5D is a standardised self-rating instrument developed by the EuroQol group as a measure of HRQoL and translated into Swedish [29]. The EQ-5D consists of a descriptive system and the EQ Visual Analogue Scale (VAS). In the questionnaire, the study participant classifies their health in five dimensions (mobility, hygiene, main activities, pains/inconvenience, worry/mood) in one of three degrees (no problems $=1$, moderate problems $=2$, difficult problems $=3$ ). The five questions in the health questionnaire make it possible to determine 243 different health conditions. The value may be negative, due to the conversion system, and varies between 1 and -0.594 . To enable health economic analyses (i.e. quality-adjusted life-years (QALY) calculations), each of the 243 health conditions has a quality of life tariff linked to it. In Sweden, we use the English tariff [30, 31]. 
EQ VAS (self-assessed health): the individual estimates a value for their current state of health on a scale graded from 0 to 100 .

\section{Katz ADL Index}

The Katz ADL Index comprises six basic functions: bathing, dressing, toileting, transfer, continence and feeding. It provides an objective method of classifying and describing an individual's health needs and outcomes. For each activity (six in total), there is a question. Each question has two possible answers: independent or dependent [32]. The Katz ADL Index is an ordinal scale ranging from A to $G$, where A means that the patient is totally independent of any assisting help. $\mathrm{F}$ is considered to be an indicator of a dependent patient. There is no 'cut-off' limit. The score will be transformed into a nominal scale ( $1-7)$ where $A=1, B=2$, etc.

\section{Computer tomography}

$\mathrm{CT}$ is the most reliable radiographic tool to classify and evaluate healing in relation to type- 2 odontoid fractures [33]. Bony union is assessed by a radiologist, independently from the study. Healing is defined as 'not visible fracture line' or 'bone bridging in fusion'.

\section{Extension flexion plain radiograph}

Dynamic flexion-extension radiographs are used to assess the functional stability - the healing - of a type- 2 odontoid fracture [34]. Instability is defined by a $>3.5-\mathrm{mm}$ listhesis and/or a relative angulation of $>11^{\circ}$ [35].

\section{Dual energy X-ray absorptiometry}

Osteoporosis will be evaluated with DXA of the hip and lumbar spine [36].

\section{Other tests}

- Blood samples (including haemoglobin, electrolytes)

- Socio-demographics, living situation (1. home, 2. nursing home, 3. hospital)

- Charlson Comorbidity Index [37, 38]

- VAS for pain (0 to 100)

\section{Data collection, management and analysis}

\section{Data collection and management}

The USOFT baseline data are recorded in a paper-based clinical record folder. Prior to inclusion, the data from each patient are collected by a spinal surgeon or a dedicated study nurse. All physician-reported outcome measurements are recorded during and after the evaluation in the folder. Patient-reported outcome measurements are recorded in the Clinical Trials extension of the Swedish Spine Registry (SweSpine) [39]. Any protocol deviations are recorded either in the case file or in the medical records; a clinical study nurse ensures that all protocol deviations and adverse events are recorded in the database.

Every allocated subject will be coded with a specific patient number. The study data will be transferred to a pre-made computer-based table (Microsoft Excel, V.15.32, Microsoft, Redmond, WA, USA) and the Clinical Trials extension of SweSpine [39]. The completed files will be stored securely in the clinical research unit for the next 15 years.

\section{Access to data}

Data safety, data quality and statistical analysis will be managed by the principal investigator who is responsible for notifying any issues that may arise during the USOFT. Data are collected and stored according to Good Clinical Practice guidelines and are available to all participating study sites. Any data safety issue occurring during the clinical trial will be reported to the principal investigator.

\section{Statistics}

For statistical analysis, $\mathrm{R}$ version 3.4.1 ( $\mathrm{R}$ Foundation for Statistical Computing, Vienna, Austria) will be used. The results will be presented according to the CONSORT Statement for non-pharmacological interventions [26]. The analysis will be performed by intention-to-treat (ITT), and sensitivity analyses will include a per-protocol analysis.

Missing values will be imputed using multiple imputation by use of chained equations as implemented in the R package "mice" with 20 iterations [40]. Details of the statistical analysis are listed in Table 1.

\section{Description of the patient groups at baseline}

The baseline features of the patients will be described with descriptive statistics using absolute numbers $(n)$ and percentages for categorical variables and the minimum, maximum, mean, SD and quartiles for quantitative variables. The number of patients crossing over to surgical treatment or dropping out from follow-up will be documented.

\section{Analysis of the primary outcome}

Multiple regression analysis of subgroup factors will allow for the determination of important factors affecting the NDI. The differences will be considered statistically significant if the $p$ value is less than 0.05 .

\section{Analysis of the secondary outcomes \\ $E Q-5 D$}

HRQoL will be evaluated with the EQ-5D by comparing the results from the two groups, using the independent $t$ test, the Mann-Whitney $U$ test or the Fisher exact test.

The differences will be considered statistically significant if the $p$ value is less than 0.05 . 
Table 1 Variables, measures and methods of analysis

\begin{tabular}{|c|c|c|c|}
\hline Variable/Outcomes & Hypothesis & Outcome measures & Methods of analysis \\
\hline Baseline data: & There is no difference between the two groups & $\begin{array}{l}\text { Gender, age, Katz } \mathrm{ADL}, \mathrm{CCl} \text {, } \\
\text { nursing home/ } \\
\text { hospitalisation, smoking } \\
\text { status }\end{array}$ & $\begin{array}{l}\text { Absolute numbers, percentages for } \\
\text { categorical variables and the minimum, } \\
\text { maximum, mean, SD and quartiles for } \\
\text { quantitative variables }\end{array}$ \\
\hline \multicolumn{4}{|l|}{ Primary: } \\
\hline Function & $\begin{array}{l}\text { There is a clinically important difference between } \\
\text { the two groups, with improvement comparing } \\
\text { baseline data with data from } 6 \text { weeks, } 12 \text { weeks, } \\
\text { and } 1 \text { year. Surgical treatment is hypothesised to be } \\
\text { superior }\end{array}$ & NDI (0-100\%) [continuous] & $\begin{array}{l}\text { Student } t \text { test, chi-square, Mann-Whitney, } \\
\text { Fisher's exact test. } \\
\text { Time-dependent differences between AUC }\end{array}$ \\
\hline \multicolumn{4}{|l|}{ Secondary: } \\
\hline $\begin{array}{l}\text { Health-related } \\
\text { quality of life }\end{array}$ & $\begin{array}{l}\text { There is a clinically important difference between } \\
\text { the two groups }\end{array}$ & EQ-5D [continuous] & $\begin{array}{l}\text { Student } t \text { test, chi-square, Mann-Whitney, } \\
\text { Fisher's exact test } \\
\text { Time-dependent differences between AUC }\end{array}$ \\
\hline Pain & $\begin{array}{l}\text { There is a clinically important difference between } \\
\text { the two groups }\end{array}$ & VAS (0-100) [continuous] & $\begin{array}{l}\text { Students } t \text { test, chi-square, Mann-Whitney, } \\
\text { Fisher exact test } \\
\text { Time-dependent differences between AUC }\end{array}$ \\
\hline Non-union & The non-union rate is lower in the surgical group & $\begin{array}{l}\text { Bone bridge in CT [binary], } \\
\text { mobility on extension- } \\
\text { flexion radiographs } \\
\text { [binary], }\end{array}$ & Chi-square test \\
\hline Mortality & The survival is greater in the surgical group & $\begin{array}{l}\text { all-cause mortality [binary], } \\
\text { time to death [continuous, } \\
\text { censored] }\end{array}$ & $\begin{array}{l}\text { Kaplan-Meier analysis, Cox regression models, } \\
\text { additional subdistribution hazards approach }\end{array}$ \\
\hline Osteoporosis & There is no difference between the two groups & $\begin{array}{l}\text { The bone density is }>2.5 \\
\text { standard deviations below } \\
\text { normal DXA T-score } \\
\text { [binary] }\end{array}$ & Chi-square \\
\hline \multicolumn{4}{|l|}{ Subgroup analysis: } \\
\hline $\begin{array}{l}\text { septuagenarians } \\
\text { vs. octogenarians } \\
\text { vs. nonagenarians }\end{array}$ & Treatment effect is diminished in nonagenarians & & \\
\hline $\begin{array}{l}\text { Goel-Harms } \\
\text { technique vs. } \\
\text { Magerl technique }\end{array}$ & There is no difference between the two groups & & \\
\hline Male vs. female & There is no difference between the two groups & & \\
\hline \multicolumn{4}{|l|}{ Sensitivity analysis: } \\
\hline $\begin{array}{l}\text { Per-protocol } \\
\text { analysis }\end{array}$ & & All outcomes & $\begin{array}{l}\text { Students } t \text { test, chi-square, Mann-Whitney, } \\
\text { Fisher exact test }\end{array}$ \\
\hline $\begin{array}{l}\text { Adjusting for } \\
\text { baseline covariates }\end{array}$ & All outcomes & & $\begin{array}{l}\text { Uni-and multivariate adjusted logistic } \\
\text { regression and Cox proportional hazard } \\
\text { models }\end{array}$ \\
\hline $\begin{array}{l}\text { Adjusting for } \\
\text { mortality }\end{array}$ & All outcomes & & subdistribution hazards approach \\
\hline
\end{tabular}

CT computed tomography, NDI Neck Disability Index, EQ-5D EuroQol, VAS Visual Analogue Scale, CCI Charlson Comorbidity Index, Katz ADL Activities of Daily Living score according to Katz, DXA double x-ray absorptiometry, $A U C$ area under the curve

\section{Non-union}

A chi-squared test will be used to compare the non-union rate between the two groups.

\section{VAS}

The VAS will be evaluated using the $t$ test, the Mann-Whitney $U$ test or Fisher's exact test.

\section{Survival}

The Kaplan-Meier method will be used for the determination of the non-surgical and surgical treatment mean survival at 1 year. Proportional survival differences according to treatment will be tested with the chi-squared test. With the Cox proportional hazards regression method, covariates contributing to survival will be entered in univariate 
and multivariate models, if the hazard ratio presents with a $95 \%$ confidence interval $(\mathrm{CI})$.

\section{Subgroup analysis}

We will perform a separate analysis of participant socio-demographics, type-2 odontoid fracture subgroup, the specific type of surgery (categorical: Magerl-Atlas claw or Goel-Harms) and osteoporosis status (DXA score).

\section{Sample size}

Up to 50 participants will be included in the study, based on the following calculation of sample size:

The MCID of the NDI is 3.5 points (7\%) and the SD is 3.5 points [28]. Thus, 16 participants are needed in each group to reach $80 \%$ power with a two-sided significance level of $p<0.05$ in a (clinically important) superiority study design. Adjusting for 1-year mortality among those aged $\geq 70$ years with a non-surgical axis fracture treatment of $29 \%$ (Robinson AL et al. Spine J. 2018; in press), eight additional participants must be recruited in each group. A minimum of 24 subjects must be included in each group.

\section{Monitoring \\ Data monitoring}

An interim analysis will be performed on the primary endpoint (NDI improvement) when 30 patients have been randomised and completed the 1-year follow-up. The interim analysis will be performed by a statistician. The statistician will report to the $R \& D$ Council of the Orthopaedic Department at Uppsala University Hospital (FoUU rådet). The R\&D Council will have unblinded access to all data. The council, which will decide on the continuation of the trial, will report to the Central Ethics Committee if the trial is stopped prematurely [41]. The decision regarding study discontinuation follows the Haybittle-Peto stopping rule: if treatment effects cause an NDI improvement difference between surgical and non-surgical groups with $p<0.001$ in the interim analysis, the trial will be stopped [42].

\section{Harm}

If the attending physician suspects a serious adverse event (SAE), the patient's follow-up will not be discontinued. An SAE is considered if it results in the following outcomes: in-hospital death, life-threatening event or neurological worsening. In case of severe adverse advents, the investigator in charge of the study will inform the $R \& D$ Council. The council will then decide on whether to continue the trial, reporting to the Central Ethics Committee if the trial is stopped prematurely.

\section{Auditing}

The SweSpine board (governed by the Swedish Society of Spinal Surgeons) reviews the patient-reported outcome measure forms and clinical data at regular intervals.

\section{Ethics and dissemination Research ethics approval}

This study is conducted in compliance with the current version of the Declaration of Helsinki. The research project was approved by the Uppsala Regional Ethics Committee on 18 May 2011 (registration no. 2011/068).

\section{Protocol amendments}

Modifications to the protocol require approval by the Regional Ethics Committees, will be registered with ClinicalTrials.gov, and will be communicated to the participating university hospitals.

\section{Consent or assent}

Prior to the trial, patients must consent orally and in writing after the possible consequences of the clinical study are explained in an understandable way. All documents must be written in Swedish. If the patient is unable to give informed consent, a close relative will be asked to take the decision instead. The patient will receive a copy of the signed patient information. A patient may withdraw from the study at any time if they are unwilling to continue on the trial. In this case, the data from a patient who requests full withdrawal will not be considered in the data analysis.

\section{Confidentiality}

All original documents will be kept in the clinical research unit for the next 15 years. The study data will be handled in line with by the European Directive 95/46/ EC on data protection. All original records will be kept on file at the trial sites or coordinating data managing centre for 10 years. The electronic clinical trial database in SweSpine will be kept on file for at least 10 years.

\section{Access to data}

The principal investigators have full access to the final datasets. There are no contractual agreements that limit such access for investigators.

\section{Dissemination policy}

The study results will be published in peer-reviewed medical journals, and communicated at medical conferences. The original principal investigators $A R, Y R$ and $\mathrm{CO}$ will appear as co-authors on all publications based on results from this study cohort. The participant-level dataset and the statistical code will not be publicly available and remain with the principal investigators. 


\section{Discussion}

This is the first randomised controlled study on the treatment of type- 2 odontoid fractures in the elderly. The key results of this study will be applicable to evidence-based guidelines and benefit the growing elderly population.

Since surgery among the elderly is associated with a 4-day longer hospital stay, the results of this randomised controlled trial (RCT) will have direct implications on health policy and medical decision-making (unpublished data).

Function and HRQoL are important pillars of value-based care. Thus, this study uses a functional patient-reported questionnaire as its primary endpoint. We discarded mortality as the primary endpoint due to the fragility of patients above 70 years of age, where hazard causes overlap and sample size issues arise [43].

\section{Limitations}

This randomised controlled study employs an open-label design, where both the investigator and the patient know which treatment they will receive. Unfortunately, the open-label design has an inherent selection bias, where patients can drop out during enrolment or give informed consent prior to inclusion in this study.

A review of the allocation concealment methods of major medical journals in 2015 found that 19\% of trials involved an inadequate allocation method and $22 \%$ were without appropriate reporting of the randomisation method [44]. Our protocol uses SNOSE allocation concealment and simple randomisation. The sealed envelope technique requires good clinical practice and discipline of the part of the enrolling physician, since translucency and premature opening can corrupt the randomisation process [45]. Simple randomisation avoids deciphering block randomisation but risks different sample sizes in treatment and control groups. Transparency of the randomisation process and close supervision of the randomisation process by the principle investigator and the R\&D Council will control the quality of this RCT.

One-year progression-free survival and 1-year all-cause mortality are common primary endpoints for RCTs. Due to the frailty of the elderly study participants, an overlap of an unrelated and natural cause of death with injury-related mortality causes high variation and would require a significantly greater sample size. Since HRQoL defines the value of life years gained, this study uses the NDI as the primary endpoint, with EQ-5D and survival as secondary endpoints.

We have planned to deal with dropouts for death in our sample size calculation, adopting an inflation rate. However, death will represent an important competing event. It is possible that if surgery has a favourable impact on mortality, more people will die in the control group, and earlier. These people who die might be those more compromised. This means that people in the control group who survive at 1 year might be those who are healthier, which might dilute the actual effect of the intervention on disability. To adjust for competing events we aim to use a subdistribution hazards approach to adjust for mortality [46].

The results from this study will provide overdue evidence regarding the treatment of type-2 odontoid fractures in the elderly. The QALYs gained with optimal treatment will support policy-makers and clinicians with their informed decisions.

\section{Trial status}

This protocol been approved and registered with the Uppsala Regional Ethics Committee on 18 May 2011(no. 2011/ 068). It was registered retrospectively with ClinicalTrials.gov on 25 August 2015 (NCT02789774; pre-results). Patient inclusion for USOFT started in February 2012 in the Department of Surgical Sciences at Uppsala University Hospital, Uppsala, Sweden, and in October 2014 in the Department of Spine Surgery at Malmö University Hospital, Malmö, Sweden. Inclusion of other departments over the course of time is planned. Recruitment is planned to be completed before 31 December 2018.

\section{Additional files}

Additional file 1: Standard Protocol Items: Recommendations for Interventional Trials (SPIRIT) 2013 Checklist: recommended items to address in a clinical trial protocol and related documents. (DOC $122 \mathrm{~kb}$ )

Additional file 2: Model informed consent form given to participants or surrogates (the original form uses the Swedish language). (PDF 60 kb)

\section{Abbreviations}

ADL: Activities of daily living; ASA: Classification according to the American Society of Anaesthesiologists; BMI: Body Mass Index; C: Cervical vertebrae; CCl: Charlson Comorbidity Index; Cl: Confidence interval; CONSORT: Consolidated Standards of Reporting Trials; CT: Computed tomography; DXA: Double x-ray absorptiometry; EQ-5D: EuroQol group questionnaire; HR: Hazard ratio; HRQoL: Health-related quality of life; ICD-10: International Classification of Diseases; ITT: Intention-to-treat; IV: Intravenous; MCID: Minimal clinically important difference; NDI: Neck Disability Index; NPR: National Patient Registry (patientregistret, Socialstyrelsen); OR: Odds ratio; R\&D: Research and development; RCT: Randomised controlled trial; RR: Risk ratio; RRR: Relative risk reduction; SAE: Serious adverse events; SCl: Spinal cord injury; SNOSE: Sequentially numbered, opaque sealed envelope; SPSS: Statistical Package for the Social Sciences; SweSpine: Swedish Spine Registry; USOFT: Uppsala Study on Odontoid Fracture Treatment; VAS: Visual Analogue Scale

\section{Acknowledgements}

The authors thank the study nurse Mrs. Catharina Strömstedt for the excellent work regarding the data management of this study.

\section{Funding}

This work was supported by the Swedish Society of Spinal Surgeons (2011) and the Thuréus Grant for Geriatric Research (2014).

Availability of data and materials

The datasets generated and/or analysed during the current study are not publicly available due to the limitations of Swedish data protection legislations, but are available from the corresponding author on reasonable request. 


\section{Authors' contributions}

All authors have made substantial contributions to the conception or design of the protocol. AR drafted the manuscript. GS, YR and CO revised it critically for important intellectual content. All authors approved the final version and agreed to be accountable for all aspects of the work in ensuring that questions related to the accuracy or integrity of any part of the work are appropriately investigated and resolved. All authors read and approved the final manuscript.

\section{Authors' information}

$\mathrm{CO}$ is board member of the Cervical Spine Research Society - Europe.

\section{Ethics approval and consent to participate}

This protocol was approved by the Uppsala Regional Ethics Committee on 23 March 2011 (no. 2011/068).

\section{Consent for publication}

We include the consent for publication in the informed consent for study participation, which is obtained at the time of enrolment from every patient.

\section{Competing interests}

AR, YR and CO have given paid lectures to physician training courses organised by Medtronic Inc. (Dublin, Ireland) and DePuy Synthes (Johnson \& Johnson, Zuchwil, Switzerland).

\section{Publisher's Note}

Springer Nature remains neutral with regard to jurisdictional claims in published maps and institutional affiliations.

\section{Author details}

'Department of Surgical Sciences, Uppsala University Hospital, Uppsala, Sweden. ${ }^{2}$ Stockholm Spine Center, Stockholm, Sweden. ${ }^{3}$ Schön Clinic Hamburg Eilbek, Hamburg, Germany. ${ }^{4}$ Dept. of Research and Development, Armed Forces Centre for Defence Medicine, Västra Frölunda, Gothenburg, Sweden. ${ }^{5}$ Stockholm Spine Center, Löwenströmska Hospital, 19489 Stockholm, Upplands Väsby, Sweden.

\section{Received: 2 November 2017 Accepted: 16 May 2018}

\section{Published online: 22 August 2018}

\section{References}

1. Mekata K, Takigawa T, Matsubayashi J, Toda K, Hasegawa Y, Ito Y. The effect of the cervical orthosis on swallowing physiology and cervical spine motion during swallowing. Dysphagia. 2016;31:74-83.

2. Robinson A-L, Möller A, Robinson Y, Olerud C. C2 fracture subtypes, incidence, and treatment allocation change with age: a retrospective cohort study of 233 consecutive cases. Biomed Res Int. 2017;2017:7.

3. Graffeo CS, Perry A, Puffer RC, Carlstrom LP, Chang W, Mallory GW, Clarke MJ. Deadly falls: operative versus nonoperative management of Type II odontoid process fracture in octogenarians. J Neurosurg Spine. 2017;26:4-9.

4. Robinson Y, Robinson AL, Olerud C. Systematic review on surgical and nonsurgical treatment of type II odontoid fractures in the elderly. Biomed Res Int. 2014:2014:231948.

5. Molinari RW, Dahl J, Gruhn WL, Molinari WJ. Functional outcomes, morbidity, mortality, and fracture healing in 26 consecutive geriatric odontoid fracture patients treated with posterior fusion. J Spinal Disord Tech. 2013;26:119-26.

6. Seybold EA, Bayley JC. Functional outcome of surgically and conservatively managed dens fractures. Spine (Phila Pa 1976). 1998;23: 1837-45. discussion 1845-1836

7. Vaccaro AR, Kepler CK, Kopjar B, Chapman J, Shaffrey C, Arnold P, Gokaslan Z, Brodke D, France J, Dekutoski M, et al. Functional and quality-of-life outcomes in geriatric patients with type-II dens fracture. J Bone Joint Surg Am. 2013;95:729-35

8. Robinson A-L, Olerud C, Robinson Y. Epidemiology of C2 fractures in the 21st century: a National Registry cohort study of 6,370 patients from 1997 to 2014. Adv Orthop. 2017;2017:8.

9. Alhashash M, Shousha M, Gendy H, Barakat AS, Boehm H. Percutaneous Posterior Transarticular Atlantoaxial Fixation for the Treatment of Odontoid Fractures in the Elderly: A Prospective Study. Spine (Phila Pa 1976). 2018; 43(11):761-6

10. Vaccaro AR, Oner C, Kepler CK, Dvorak M, Schnake K, Bellabarba C, Reinhold M, Aarabi B, Kandziora F, Chapman J, et al. AOSpine thoracolumbar spine injury classification system: fracture description, neurological status, and key modifiers. Spine (Phila Pa 1976). 2013:38:2028-37.

11. Deng H, Yue JK, Upadhyayula PS, Burke JF, Suen CG, Chan AK, Winkler EA Dhall SS. Odontoid fractures in the octogenarian: a systematic review and meta-analysis. J Neurosurg Sci. 2016;60(4):543-55.

12. Chan A-W, Tetzlaff JM, Gøtzsche PC, Altman DG, Mann H, Berlin JA, Dickersin K, Hróbjartsson A, Schulz KF, Parulekar WR, et al. SPIRIT 2013 explanation and elaboration: guidance for protocols of clinical trials. BMJ. 2013;346

13. Anderson LD, D'Alonzo RT. Fractures of the odontoid process of the axis. J Bone Joint Surg Am. 1974;56:1663-74.

14. Greene KA, Dickman CA, Marciano FF, Drabier JB, Hadley MN, Sonntag VK. Acute axis fractures. Analysis of management and outcome in 340 consecutive cases. Spine (Phila Pa 1976). 1997;22:1843-52.

15. Grauer JN, Shafi B, Hilibrand AS, Harrop JS, Kwon BK, Beiner JM, Albert TJ, Fehlings MG, Vaccaro AR. Proposal of a modified, treatment-oriented classification of odontoid fractures. Spine J. 2005;5:123-9.

16. Osman A, Alageli NA, Short DJ, Masri WSE. Conservative management of odontoid peg fractures, long term follow up. J Clin Orthop Trauma. 2017:8:103-6.

17. Koivikko MP, Kiuru MJ, Koskinen SK, Myllynen P, Santavirta S, Kivisaari L. Factors associated with nonunion in conservatively-treated type-II fractures of the odontoid process. J Bone Joint Surg Br Vol. 2004;86-B:1146-51.

18. Doyle DJ, Garmon E. American Society of Anesthesiologists Classification (ASA Class). In: StatPearls. Treasure Island (FL): StatPearls Publishing LLC; 2017.

19. Saklad MDM. Grading of patients for surgical procedures. Anesthesiology. 1941;2:281-4.

20. Olerud S, Olerud C. The C1 claw device: a new instrument for C1-C2 fusion Eur Spine J. 2001;10:345-7.

21. Goel A, Desai Kl, Muzumdar DP. Atlantoaxial fixation using plate and screw method: a report of 160 treated patients. Neurosurgery. 2002;51:1351-6. discussion 1356-1357

22. Harms J, Melcher RP. Posterior C1-C2 fusion with polyaxial screw and rod fixation. Spine (Phila Pa 1976). 2001;26:2467-71.

23. Wright NM. Posterior C2 fixation using bilateral, crossing C2 laminar screws: case series and technical note. J Spinal Disord Tech. 2004;17:158-62.

24. Vernon $\mathrm{H}$, Mior $\mathrm{S}$. The Neck Disability Index: a study of reliability and validity. J Manip Physiol Ther. 1991;14:409-15.

25. Ackelman $\mathrm{BH}$, Lindgren $\mathrm{U}$. Validity and reliability of a modified version of the Neck Disability Index. J Rehabil Med. 2002;34:284-7.

26. Boutron I, Altman DG, Moher D, Schulz KF, Ravaud P. CONSORT Statement for randomized trials of nonpharmacologic treatments: a 2017 update and a CONSORT extension for nonpharmacologic trial abstracts. Ann Intern Med. 2017:167:40-7.

27. Torgerson DJ, Roberts C. Randomisation methods: concealment. BMJ. 1999; 319:375-6.

28. Pool JJ, Ostelo RW, Hoving JL, Bouter LM, de Vet HC. Minimal clinically important change of the Neck Disability Index and the Numerical Rating Scale for patients with neck pain. Spine (Phila Pa 1976). 2007;32:3047-51.

29. Burstrom K, Johannesson M, Diderichsen F. Swedish population healthrelated quality of life results using the EQ-5D. Qual Life Res. 2001;10:621-35.

30. Orgeta V, Edwards RT, Hounsome B, Orrell M, Woods B. The use of the EQ$5 \mathrm{D}$ as a measure of healthrelated quality of life in people with dementia and their carers. Qual Life Res. 2015:24(2):315-24

31. Dolan P, Roberts J. Modelling valuations for EQ-5D health states: an alternative model using differences in valuations. Med Care. 2002:40:442-6.

32. Katz S, Akpom CA. 12. Index of ADL. Med Care. 1976;14:116-8.

33. Koller H, Kolb K, Zenner J, Reynolds J, Dvorak M, Acosta F, Forstner R, Mayer M, Tauber M, Auffarth A, et al. Study on accuracy and interobserver reliability of the assessment of odontoid fracture union using plain radiographs or CT scans. Eur Spine J. 2009;18:1659-68.

34. Dvorak J, Froehlich D, Penning L, Baumgartner H, Panjabi MM. Functional radiographic diagnosis of the cervical spine: flexion/extension. Spine (Phila Pa 1976). 1988;13:748-55

35. Khan SN, Erickson G, Sena MJ, Gupta MC. Use of flexion and extension radiographs of the cervical spine to rule out acute instability in patients with negative computed tomography scans. J Orthop Trauma. 2011;25:51-6.

36. Blake GM, Fogelman I. The role of DXA bone density scans in the diagnosis and treatment of osteoporosis. Postgrad Med J. 2007;83:509-17.

37. Charlson M, Szatrowski TP. Peterson J, Gold J. Validation of a combined comorbidity index. J Clin Epidemiol. 1994;47:1245-51. 
38. Charlson ME, Pompei P, Ales KL, MacKenzie CR. A new method of classifying prognostic comorbidity in longitudinal studies: development and validation. J Chronic Dis. 1987;40:373-83.

39. Strömqvist B, Fritzell P, Hägg O, Jönsson B, Sandén B, Swedish Society of Spinal S. Swespine: the Swedish spine register: the 2012 report. Eur Spine J. 2013;22:953-74.

40. White IR, Royston P, Wood AM. Multiple imputation using chained equations: Issues and guidance for practice. Stat Med. 2011;30:377-99.

41. Tyson JE, Pedroza C, Wallace D, D'Angio C, Bell EF, Das A. Stopping guidelines for an effectiveness trial: what should the protocol specify? Trials. 2016;17:240.

42. Pocock SJ. When (not) to stop a clinical trial for benefit. JAMA. 2005;294: 2228-30.

43. White AP, Hashimoto R, Norvell DC, Vaccaro AR. Morbidity and mortality related to odontoid fracture surgery in the elderly population. Spine (Phila Pa 1976). 2010;35:S146-57.

44. Clark L, Fairhurst C, Torgerson DJ. Allocation concealment in randomised controlled trials: are we getting better? BMJ. 2016;355

45. Kennedy ADM, Torgerson DJ, Campbell MK, Grant AM. Subversion of allocation concealment in a randomised controlled trial: a historical case study. Trials. 2017;18:204.

46. Fine JP, Gray RJ. A proportional hazards model for the subdistribution of a competing risk. J Am Stat Assoc. 1999;94:496-509.

Ready to submit your research? Choose BMC and benefit from:

- fast, convenient online submission

- thorough peer review by experienced researchers in your field

- rapid publication on acceptance

- support for research data, including large and complex data types

- gold Open Access which fosters wider collaboration and increased citations

- maximum visibility for your research: over $100 \mathrm{M}$ website views per year

At BMC, research is always in progress.

Learn more biomedcentral.com/submissions 